\title{
Modular Multilevel Converter Based Induction Machine Drive
}

\author{
Yin Li, Student Member, IEEE, Lingling Fan, Senior Member, IEEE
}

\begin{abstract}
This paper proposes that a medium voltage level power Modular Multilevel Converter (MMC) based induction machine drive. MMC replaces a two-level voltage source converter (VSC) to drive an induction motor because of its high voltage power range. A designed 5-level three-phase dc-to-ac MMC is analyzed on the circular topology. The indirect field orientated vector control (FOC) is used to control the motor. This paper also compares the vector control loops with a constant and a dynamic rotor flux as feedforward. The motor drive system is simulated in MATLAB/SimPowerSystems. The simulation results validate the control design of the motor drive with two different vector control loops.
\end{abstract}

Index Terms-Modular multilevel converter, field orientation vector control, constant and dynamic rotor flux.

\section{INTRODUCTION}

With the rapid development of the high-voltage power applications, a newer kind of VSC, modular multilevel converter (MMC) has been applied in HVDC systems [1], [2]. Till now, MMC is used more and more widely in industrial area. In the renewable energy market, MMC can replace a twolevel or three-level VSC to drive a wind machine [3]. Study on motor drive with MMC in this paper can be applied to wind farms. Compared with the traditional two-level VSC, the MMC contains more than one sub-module (SM) in cascaded connection on each arm [4]. The structure of a three-phase dc-to-ac MMC with a detailed sub-module is shown in Fig.1. The sub-module is a simple buck converter with two IGBT and a dc capacitor, $C_{s m}$. MMC has two main advantages due to its special structure. First, the cascaded connection of sub-modules makes the MMC intended for any voltage power level requirement, especially for the medium and high voltage power applications [4]-[6]. Second, the high-level number of the submodules can reduce the effect of the harmonic distortion and the switching frequency [7]-[9]. For simulation based studies, MMC has a drawback on simulation time. The huge number of sub-modules corresponds to the huge effort of computation. Therefore, for simulation studies, the range of the number of sub-modules in many experiments is from 2 to 8 [1], [2], [10]-[12]. In this paper, a 5-level MMC is chosen.

Indirect field oriented vector control (FOC) [13] is very popular in motor drives. It can overcome the inherent coupling effect in scalar control and realize torque/flux control speedily. The vector control is based on the rotor flux reference frame where $d$-axis is aligned with the rotor flux. The rotor flux may be considered as a constant due to flux control. The response

Y. Li and L. Fan are with Dept. of Electrical Engineering, University of South Florida, Tampa FL 33620. Emails: yin@mail.usf.edu, linglingfan@usf.edu.

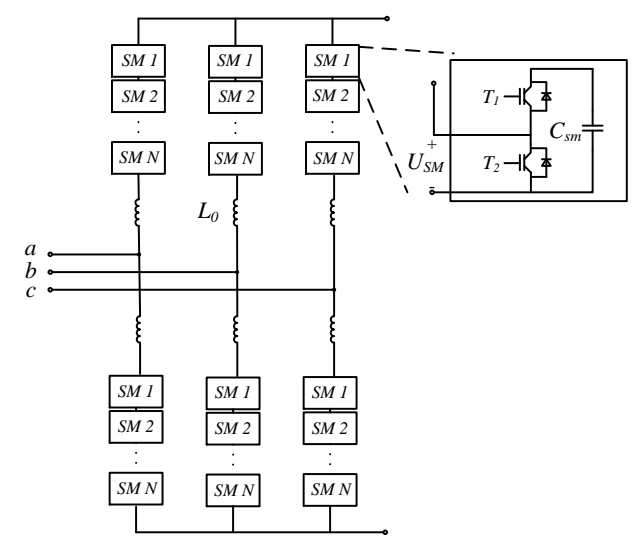

Fig. 1. The basic structure of three-phase MMC with the sub-module.

speed is relative slow in the outer control loop of the FOC, so this assumption can be used when designing the inner loop. Nevertheless, the fast response speed of the inner loop will cause this assumption not to be rigorous. In this paper, two kinds of the inner loops are compared based on with or without a constant rotor flux assumption.

This paper addresses two main issues. One is to test MMC's control performance on motor drive. Another is if a vector control considering a dynamic rotor flux is better than one with a constant rotor flux. The following sections will analyze the basic structure and the circular interactions of the MMC. They also explain how two kinds of the vector control loop is designed and compared. Simulation results in Matlab/SimPowerSystems are given.

\section{MMC TOPOLOGY AND CONTROL STRUCTURE}

Fig.1 shows the topology of a three-phase dc-to-ac modular multilevel converter. The right side is the input of MMC which should be connected to a dc power supply. The output of MMC is on the left side and can be applied to a three-phase grid application. Because it is a three-phase converter, there are six arms and each of them contains a group of the cascade connected sub-modules. The number of sub-modules, $N$, is depended on the specific voltage level requirement. On each arm , there is also an inductor marked $L_{0}$ which can filter some high-order harmonics from the circulating current. Its value cannot be too high because of the large voltage drop and high cost of high-voltage inductor, although the high inductance can reduce the amplitude of one undesired component of the arm current, the circulating current [5]. 
In this section, the analysis uses Phase $\mathrm{A}$ as the example. Fig.2 shows the two equivalent circuits of Phase A to analyze the circular interactions. Phase A has two arms, so $i_{a p}$ and $i_{a n}$ are denoted as the upper and lower arm currents which contains two parts. One is inner current which just flows inside the phase unit, $i_{d i f f, a}$, and another one is the MMC output current, $i_{a_{-} g r i d}$, shown in Fig.2 b). Because $i_{a p}$ and $i_{a n}$ are symmetric, $i_{a_{-} \text {grid }}$ is divided equally into each of them. Therefore, due to KCL, $i_{a p}$ and $i_{a n}$ can be expressed as

$$
\left\{\begin{array}{l}
i_{a p}(t)=\frac{i_{a-g r i d}}{2}+i_{d i f f, a} \\
i_{a n}(t)=-\frac{i_{a-g r i d}}{2}+i_{d i f f, a}
\end{array}\right.
$$

Moreover, $i_{a_{-} g r i d}$ is a sinusoidal wave with the fundamental frequency to supply the grid application and $i_{d i f f, a}$ includes a dc component, $I_{a d}$, and the circulating current with high-order harmonics, $i_{c i r}$.

The voltage dropping on each arm inductor, $L_{0}$, is caused by $i_{d i f f, a}$, and it is named as the inner unbalanced voltage, $u_{\text {diff,a }}$. Based on KVL and Fig.2 a), the arm voltages can be expressed as

$$
\left\{\begin{array}{l}
u_{a p}=\frac{U_{d c}}{2}-L_{0} \frac{d i_{d i f f, a}}{d t}-v_{a \_g r i d} \\
u_{a n}=\frac{U_{d c}}{2}-L_{0} \frac{d i_{d i f f, a}}{d t}+v_{a_{-} g r i d}
\end{array}\right.
$$

where $U_{d c}$ is the dc voltage source and $v_{a \_g r i d}$ is the output voltage of the MMC. The sum of the upper and lower arm voltages should be equal to the dc voltage source. The half of the difference between them is the output voltage, $v_{a_{-} g r i d}$, and it is also named as the inner emf, $e_{a}$. It is used as the control voltage in vector control. An additional control block to suppress the circulating current is also included to adjust

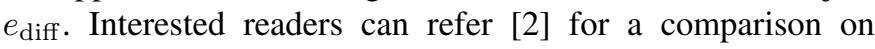
control structures of a two-level VSC and MMC. For motor control, $e_{a b c}$ will be the final controller output from the FOC.

$$
\left\{\begin{array}{l}
u_{a n}+u_{a a}=U_{d c}+2 u_{d i f f, a} \\
\frac{u_{a n}-u_{a p}}{2}=v_{a \_g r i d}=e_{a}
\end{array}\right.
$$

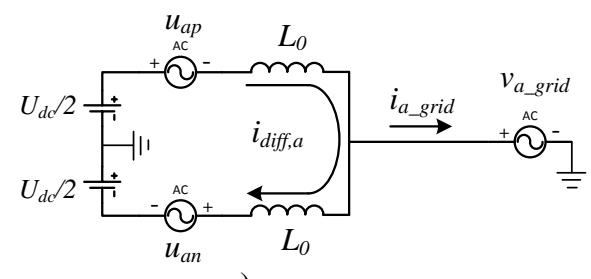

a)

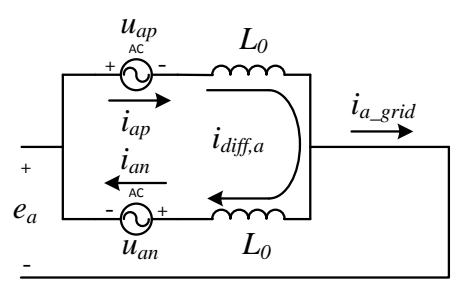

b)

Fig. 2. a) the equivalent circuit for $u_{a n}+u_{a p}$; b) the equivalent circuit for $u_{a n}-u_{a p}$

\section{The Rotor Field Orientated Vector CONTROL}

The whole motor drive system is designed like Fig.3. The bottom part is the control loop which has the outer control loop and the inner control loop. The outer loop is controlled by the rotor flux and frequency. The inner loop is controlled by the stator current. How the control loop is designed will be analyzed in this section. The superscript of the current or flux, $s$ or $e$, means the stationary frame or synchronous frame. The subscript, $s$ or $r$, means stator side and rotor side. The subscript, $q$ or $d$, means the components on q-axis or d-axis. The values measured from the induction motor in SimPowerSystems are: $\varphi_{q r}^{s}, \varphi_{d r}^{s}, i_{q s}^{s}, i_{d s}^{s}$ and $\omega_{r}$ shown in Fig.3.

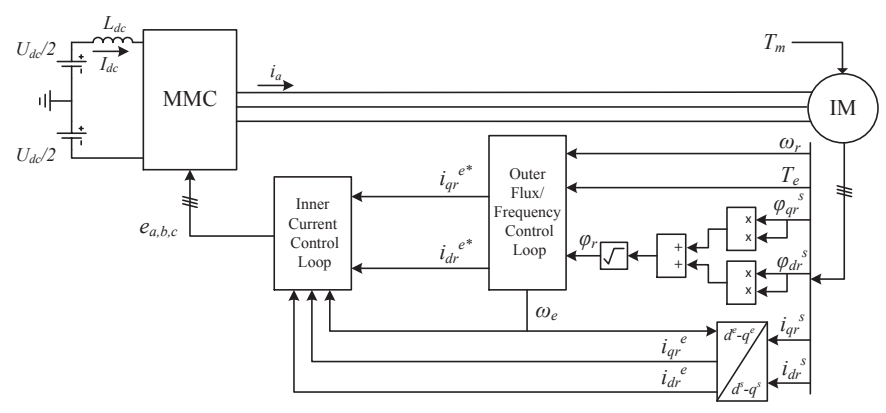

Fig. 3. Motor The whole motor drive system with MMC

\section{A. Outer Flux and Frequency Control}

First, the relation between the rotor flux and the stator current should be derived. The flux linkage expressions in terms of the currents can be written as follows:

$$
\begin{aligned}
& \varphi_{q s}^{e}=L_{l s} i_{q s}^{e}+L_{m}\left(i_{q s}^{e}+i_{q r}^{e}\right)=L_{s} i_{q s}^{e}+L_{m} i_{q r}^{e} \\
& \varphi_{d s}^{e}=L_{l s} i_{d s}^{e}+L_{m}\left(i_{d s}^{e}+i_{d r}^{e}\right)=L_{s} i_{d s}^{e}+L_{m} i_{d r}^{e} \\
& \varphi_{q r}^{e}=L_{l r} i_{q r}^{e}+L_{m}\left(i_{q s}^{e}+i_{q r}^{e}\right)=L_{r} i_{q r}^{e}+L_{m} i_{q s}^{e} \\
& \varphi_{d r}^{e}=L_{l r} i_{q r}^{e}+L_{m}\left(i_{d s}^{e}+i_{d r}^{e}\right)=L_{r} i_{d r}^{e}+L_{m} i_{d s}^{e}
\end{aligned}
$$

where $L_{l s}$ and $L_{l r}$ are the stator and rotor inductance, $L_{m}$ is the mutual inductance, $L_{s}=L_{l s}+L_{m}$, and $L_{r}=L_{l r}+L_{m}$.

The rotor circuit equation in $d q$ reference frame is:

$$
\overline{e_{r}^{e}}=0=R_{r} \overline{I_{r}^{e}}+\frac{d}{d t} \overline{\varphi_{r}^{e}}+j \omega_{s l} \overline{\varphi_{r}^{e}}
$$

where $\omega_{s l}$ is the slip frequency.

When the equation is converted into $d$ and $q$ components shown in Fig.4, (5) can be written:

$$
\begin{aligned}
& 0=e_{q r}^{e}=R_{r} i_{q r}^{e}+\frac{d}{d t} \varphi_{q r}^{e}+\omega_{s l} \varphi_{d r}^{e} \\
& 0=e_{d r}^{e}=R_{r} i_{d r}^{e}+\frac{d}{d t} \varphi_{d r}^{e}-\omega_{s l} \varphi_{q r}^{e}
\end{aligned}
$$

To replace the rotor current in (6), (4c) and (4d) can be also expressed:

$$
\begin{aligned}
i_{q r}^{e} & =\frac{1}{L_{r}} \varphi_{q r}^{e}-\frac{L_{m}}{L_{r}} i_{q s}^{e} \\
i_{d r}^{e} & =\frac{1}{L_{r}} \varphi_{d r}^{e}-\frac{L_{m}}{L_{r}} i_{d s}^{e}
\end{aligned}
$$




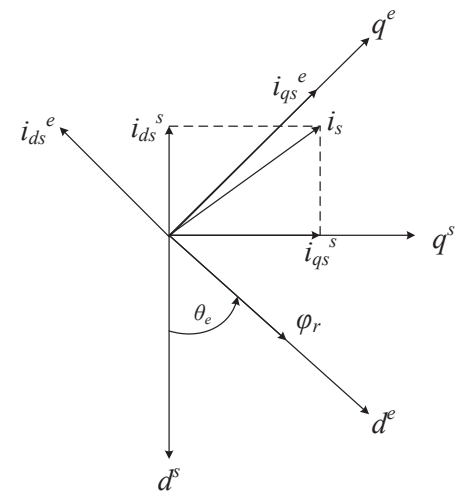

Fig. 4. Stationary frame $d^{s}-q^{s}$ to synchronous rotating frame $d^{e}-q^{e}$ transformation

Substituting (7) into (6):

$$
\begin{aligned}
& 0=\frac{d \varphi_{q r}^{e}}{d t}+\frac{R_{r}}{L_{r}} \varphi_{q r}^{e}-\frac{L_{m} L_{r}}{R_{r}} i_{q s}^{e}+\omega_{s l} \varphi_{d r}^{e} \\
& 0=\frac{d \varphi_{d r}^{e}}{d t}+\frac{R_{r}}{L_{r}} \varphi_{d r}^{e}-\frac{L_{m} L_{r}}{R_{r}} i_{d s}^{e}+\omega_{s l} \varphi_{q r}^{e}
\end{aligned}
$$

It is assumed that the rotor flux, $\hat{\varphi}_{r}$, is constant due to it slowly response, the differential of the rotor flux is zero. Then, the indirect rotor field orientation control strategy is considered in this study $\left(\varphi_{q r}^{e}=0, \varphi_{d r}^{e}=\hat{\varphi}_{r}\right)$, so (8) can be rewritten as:

$$
\begin{gathered}
\omega_{s l}=\frac{R_{r} L_{m}}{\hat{\varphi}_{r} L_{r}} i_{q s}^{e} \\
\hat{\varphi}_{r}=\varphi_{d r}^{e}=L_{m} i_{d s}^{e}
\end{gathered}
$$

The rotor flux is from two measured components.

$$
\hat{\varphi}_{r}=\sqrt{\left(\varphi_{q r}^{s}\right)^{2}+\left(\varphi_{d r}^{s}\right)^{2}}
$$

$\theta_{e}$ shown in Fig.4 is synchronous frequency angle combined with $\omega_{s l}$ and $\omega_{r}$.

$$
\theta_{e}=\int \omega_{e}=\int\left(\omega_{r}+\omega_{s l}\right) d t
$$

1) PI Controller Design For the Frequency Control: The relation between $T_{e}$ and $\omega_{r}$ can be expressed:

$$
T_{e}-T_{m}=J \frac{d \omega_{r}}{d t}+B \omega_{r}
$$

where $J$ is the inertia and $B$ is the friction factor. $T_{m}$ is the desired load torque which is zero when designing the PI controller, so the plant model for $\frac{\omega_{r}}{T_{e}}$ is $\frac{1}{J s+B}(s$ is the differential operator). To design the PI controller, the open loop transform function is:

$$
\begin{aligned}
\left(K_{p}+\frac{K_{i}}{s}\right) G(s) & =\frac{K_{p} s+K_{i}}{s} \frac{1}{J s+B} \\
& =\frac{K_{p}}{J s} \frac{s+\frac{K_{i}}{K_{p}}}{s+\frac{B}{J}}
\end{aligned}
$$

where $G(s)$ is used to present the plant model. For stabilizing the feedback control loop, the pole should be canceled using the zero of PI compensator.

$$
\left\{\begin{array} { l } 
{ \frac { K _ { i } } { K _ { p } } = \frac { B } { J } } \\
{ \frac { K _ { p } } { J } = \frac { 1 } { \tau _ { t e } } }
\end{array} \Rightarrow \left\{\begin{array}{l}
K_{p}=\frac{J}{\tau_{t e}} \\
K_{i}=\frac{B}{\tau_{t e}}
\end{array}\right.\right.
$$

where $\tau_{t_{e}}$ is the time constant for $T_{e}$ PI controller. Therefore, a determined $\tau_{t_{e}}$ can determine $K_{p}$ first; then, $K_{i}$ will be calculated based on $K_{p}$.

2) PI Controller Design For the Torque Control: Because of $\varphi_{q r}^{e}=0, \varphi_{d r}^{e}=\hat{\varphi}_{r}$, and $\hat{\varphi}_{r}$ is considered as a constant, the electric torque, $T_{e}$, is proportional to $i_{q s}^{e}$ (in my case, rotor flux is around $0.25 \mathrm{~Wb}$ ).

$$
T_{e}=\frac{3}{4} P\left(i_{q s}^{e} \varphi_{d r}^{e}-i_{d s}^{e} \varphi_{q r}^{e}\right)=\frac{3 P \hat{\varphi}_{r}}{4} i_{q s}^{e}
$$

where $P$ is the number of poles. The plant model is $\frac{3 P \hat{\varphi}_{r}}{4}$ which is a pure gain. Based on it, the closed-loop transfer function is:

$$
\begin{aligned}
T(s) & =\frac{\frac{K_{p} s+K_{i}}{s} G(s)}{1+\frac{K_{p} s+K_{i}}{s} G(s)}=\frac{\frac{G(s) K_{p}}{K_{i}} s+1}{\tau_{\text {out }} s+1} \\
\tau_{\text {out }} & =\frac{G(s) K_{p}+1}{G(s) K_{i}}=\frac{0.75 K_{p}+1}{0.75 K_{i}} \\
K_{p} & =\frac{0.75 \tau_{\text {out }} K_{i}-1}{0.75}
\end{aligned}
$$

where $\tau_{\text {out }}$ is the outer loop time constant (for both $\hat{\varphi}_{r}$ and $T_{e}$ ). When the time constant and $K_{i}$ are determined, $K_{p}$ can be calculated.

3) PI Controller Design For the Flux Control: Due to (10), the plant model is a pure gain, $L_{m}$; then the transfer function is:

$$
\begin{aligned}
T(s) & =\frac{\frac{K_{p} s+K_{i}}{s} L_{m}}{1+\frac{K_{p} s+K_{i}}{s} L_{m}}=\frac{\frac{K_{p}}{K_{i}} s+1}{\tau_{\text {out }} s+1} \\
\tau_{\text {out }} & =\frac{L_{m} K_{p}+1}{L_{m} K_{i}} \\
K_{p} & =\frac{L_{m} \tau_{\text {out }} K_{i}-1}{L_{m}}
\end{aligned}
$$

$K_{p}$ is determined after determining the time constant and $K_{i}$.

Finally, the closed loops related to frequency and flux control are shown in Fig.5. The controller parameters can be found in Tables 1-3.
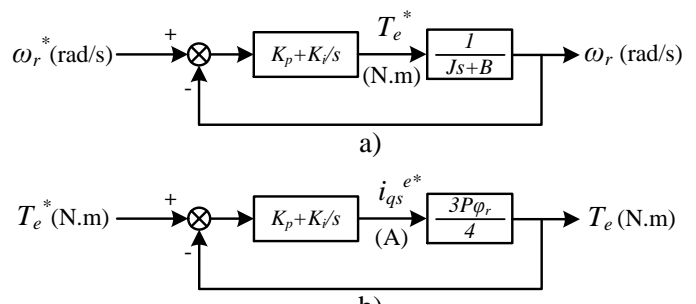

b)

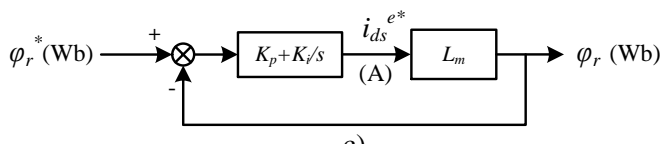

c)

Fig. 5. The closed loops related to a) $\omega_{r}$, b) $T_{e}$, and c) $\hat{\varphi}_{r}$. 


\section{B. Inner Current Control Loop}

In the inner current loops, the stator current in the synchronous frame is used to control the reference stator voltage. Hence, the relation between the stator current and voltage should be derived before designing the PI controllers. The input voltage of the induction motor in a stationary frame can be represented by a space vector.

$$
\overrightarrow{e_{s}^{s}}=R_{s} \overrightarrow{I_{s}^{s}}+\frac{d}{d t} \overrightarrow{\varphi_{s}^{s}}
$$

Transforming (19) to a synchronous frame $\left(\omega_{e}\right)$ :

$$
\bar{e}_{s}^{e}=R_{s} \bar{I}_{s}^{e}+\frac{d}{d t} \bar{\varphi}_{s}^{e}+j \omega_{e} \bar{\varphi}_{s}^{e}
$$

Separating (20) into $d-q$ components:

$$
\left\{\begin{array}{l}
e_{q s}^{e}=R_{s} i_{q s}^{e}+\frac{d}{d t} \varphi_{q s}^{e}+\omega_{e} \varphi_{d s}^{e} \\
e_{d s}^{e}=R_{s} i_{d s}^{e}+\frac{d}{d t} \varphi_{d s}^{e}-\omega_{e} \varphi_{q s}^{e}
\end{array}\right.
$$

To express $\varphi_{d s}^{e}$ and $\varphi_{q s}^{e},(4 \mathrm{c})$ and (4d) are substituted into (4a) and (4b).

$$
\left\{\begin{array}{l}
\varphi_{q s}^{e}=L_{s} i_{q s}^{e}+L_{m} \frac{\varphi_{q r}^{e}-L_{m} i_{q s}^{e}}{L_{r}}=\sigma L_{s} i_{q s}^{e}+\frac{L_{m}}{L_{r}} \varphi_{q r}^{e} \\
\varphi_{d s}^{e}=L_{s} i_{d s}^{e}+L_{m} \frac{\varphi_{d r}^{e}-L_{m} i_{d s}^{e}}{L_{r}}=\sigma L_{s} i_{d s}^{e}+\frac{L_{m}}{L_{r}} \varphi_{d r}^{e}
\end{array}\right.
$$

where $\sigma=1-\frac{L_{m}^{2}}{L_{s} L_{r}}$.

Like in the outer loop, $\hat{\varphi}_{r}$ is also assumed as a constant in the inner loop, so (10) can be applied here. Moreover, due to the rotor flux, $\varphi_{q r}^{e}=0$ and (10) are substituted into (22),

$$
\left\{\begin{array}{l}
\varphi_{q s}^{e}=\sigma L_{s} i_{q s}^{e} \\
\varphi_{d s}^{e}=\sigma L_{s} i_{d s}^{e}+\frac{L_{m}}{L_{r}} L_{m} i_{d s}^{e}=L_{s} i_{d s}^{e}
\end{array}\right.
$$

To use the current to replace the flux linkage in (21), (23) is substituted into (21):

$$
\left\{\begin{array}{l}
e_{q s}^{e}=R_{s} i_{q s}^{e}+\frac{d}{d t} \sigma L_{s} i_{q s}^{e}+\omega_{e} L_{s} i_{d s}^{e} \\
e_{d s}^{e}=R_{s} i_{d s}^{e}+\frac{d}{d t} L_{s} i_{d s}^{e}-\omega_{e} \sigma L_{s} i_{q s}^{e}
\end{array}\right.
$$

To define virtual voltages, $u_{q s}^{e}$ and $u_{d s}^{e}$, (24) can be rewritten:

$$
\left\{\begin{array}{l}
u_{q s}^{e}=e_{q s}^{e}-\omega_{e} L_{s} i_{d s}^{e}=\left(R_{s}+\sigma L_{s} s\right) i_{q s}^{e} \\
u_{d s}^{e}=e_{d s}^{e}+\omega_{e} \sigma L_{s} i_{q s}^{e}=\left(R_{s}+L_{s} s\right) i_{d s}^{e}
\end{array}\right.
$$

Based on (25), the plant models for the q-axis and d-axis current control are $\frac{1}{\sigma L_{s} s+R_{s}}$ and $\frac{1}{L_{s} s+R_{s}}$. They are used to design the PI controllers for the current control.

1) PI Controller Design For q-axis Current Control : The open loop transfer function:

$$
\left(K_{p}+\frac{K_{i}}{s}\right) G(s)=\frac{K_{p}}{\sigma L_{s} s} \frac{s+\frac{K_{i}}{K_{p}}}{s+\frac{R_{s}}{\sigma L_{s}}}
$$

Using the same way used for $T_{e}$ to determine $K_{p}$ and $K_{i}$ :

$$
\left\{\begin{array}{l}
K_{p}=\frac{\sigma L_{s}}{\tau_{i n}} \\
K_{i}=\frac{R_{s}}{\tau_{i n}}
\end{array}\right.
$$

where $\tau_{i n}$ is the time constant for the inner loop.
2) PI Controller Design For d-axis Current Control: The plant model for the d-axis is different.

$$
\begin{gathered}
\left(K_{p}+\frac{K_{i}}{s}\right) G(s)=\frac{K_{p}}{L_{s} s} \frac{s+\frac{K_{i}}{K_{p}}}{s+\frac{R_{s}}{L_{s}}} \\
\left\{\begin{array}{l}
K_{p}=\frac{L_{s}}{\tau_{i n}} \\
K_{i}=\frac{R_{s}}{\tau_{i n}}
\end{array}\right.
\end{gathered}
$$

The closed loops related to the current control are shown in Fig.6.
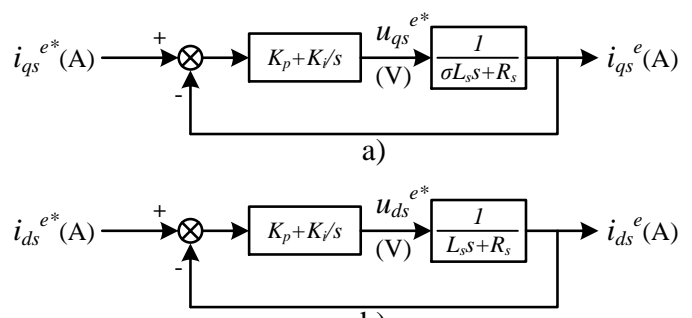

b)

Fig. 6. The closed loops related to a) q-axis current control and b) d-axis current control

A coupling operation has to be used in the control loop to produce the final desired reference voltages, $e_{q s}^{e}$ and $e_{d s}^{e}(25)$. Therefore, the whole control system is shown in Fig.7.

Actually, the much faster response speed of the inner loop causes that the effect of $\frac{d \varphi_{d r}^{e}}{d t}$ cannot be neglected. Therefore, considering a dynamic $\hat{\varphi}_{r}$ is a better and more accurate way to design the inner control loop. As a result, (10) cannot be substituted into (22). (23) is replaced by the following expression.

$$
\left\{\begin{array}{l}
\varphi_{q s}^{e}=\sigma L_{s} i_{q s}^{e} \\
\varphi_{d s}^{e}=\sigma L_{s} i_{d s}^{e}+\frac{L_{m}}{L_{r}} \hat{\varphi}_{r}
\end{array}\right.
$$

Substituting (30) into (21),

$$
\left\{\begin{array}{l}
e_{q s}^{e}=R_{s} i_{q s}^{e}+\frac{d}{d t} \sigma L_{s} i_{q s}^{e}+\omega_{e} L_{s} i_{d s}^{e}+\omega_{e} \frac{L_{m}}{L_{r}} \hat{\varphi}_{r} \\
e_{d s}^{e}=R_{s} i_{d s}^{e}+\frac{d}{d t} \sigma L_{s} i_{d s}^{e}-\omega_{e} \sigma L_{s} i_{q s}^{e}
\end{array}\right.
$$

The virtual voltages should be redefined based on (31).

$$
\left\{\begin{array}{l}
u_{q s}^{e}=e_{q s}^{e}-\omega_{e} L_{s} i_{d s}^{e}-\omega_{e} \frac{L_{m}}{L_{r}} \hat{\varphi}_{r}=\left(R_{s}+\sigma L_{s} s\right) i_{q s}^{e} \\
u_{d s}^{e}=e_{d s}^{e}+\omega_{e} \sigma L_{s} i_{q s}^{e}=\left(R_{s}+\sigma L_{s} s\right) i_{d s}^{e}
\end{array}\right.
$$

(32) shows that the plant models for the new inner current control are the same as it for q-axis current control in the previous inner control, $\frac{1}{\sigma L_{s} s+R_{s}}$, so the determined $K_{p}$ and $K_{i}$ from (29) can be also applied for both $d q$ current control in the new inner loop. However, $e_{q s}^{e}$ is coupled with one more component, $\omega_{e} \frac{L_{m}}{L_{r}} \hat{\varphi}_{r}$ (31), so the new structure of the inner loop is improved shown by the red dash line parts in Fig. 7.

\section{Simulation Results FROM MATLAB/SIMPOWERSYSTEMS}

To verify that the MMC can replace the traditional VSC to drive an induction motor with the vector control, a detailed model is developed in the SimPowerSystems of MATLAB. Fig. 3 shows the structure of the simulated system. Between 


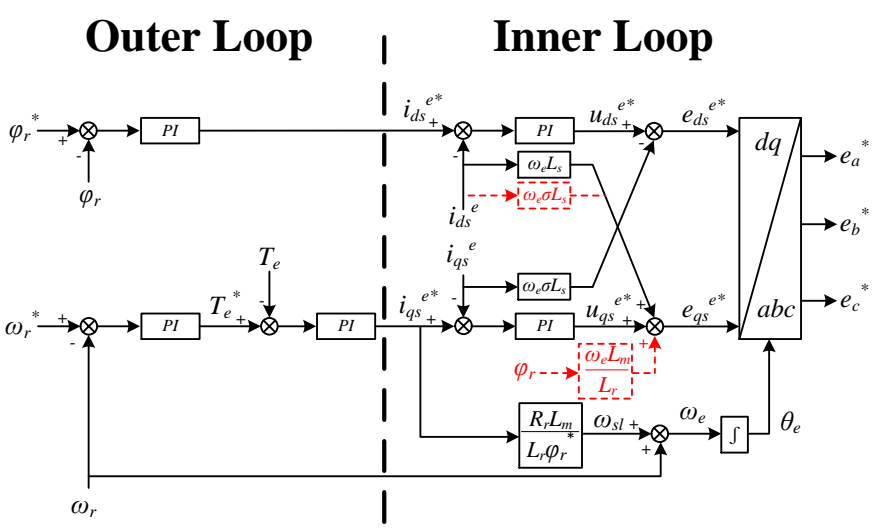

Fig. 7. The structure of the vector control system (The red dash line parts are the improvements for the dynamic $\hat{\varphi_{r}}$ ).

TABLE I

\begin{tabular}{|l|c|}
\hline Parameter & Value \\
\hline Rated DC-link voltage of MMC & $250 \mathrm{~V}$ \\
\hline Arm inductance $L_{0}$ & $0.002 \mathrm{H}$ \\
\hline DC side inductance $L_{d c}$ & $0.005 \mathrm{H}$ \\
\hline Number of submodules of each arm $(\mathrm{N})$ & 4 \\
\hline Capacitance of each sub-module $\left(C_{s m}\right)$ & $2.5 \mathrm{mF}$ \\
\hline Switching frequency & $1050 \mathrm{~Hz}$ \\
\hline
\end{tabular}

DC voltage source and MMC, there is a dc inductor which filters some harmonics of the dc current. The main values of the MMC are listed in Table 1 and the values of the induction motor are listed in Table 2. The values for the designed PI controllers are determined by the equations in Section III listed in Table 3.

TABLE II

\begin{tabular}{|l|c|}
\hline Parameter & Value \\
\hline Nominal power, voltage(rms,line-line) & $2238 \mathrm{VA}, 220 \mathrm{~V}$ \\
\hline Nominal frequency & $60 \mathrm{~Hz}$ \\
\hline Stator resistance $\left(R_{s}\right)$, inductance $\left(L_{s}\right)$ & $0.435 \Omega, 0.002 \mathrm{H}$ \\
\hline Rotor resistance $\left(R_{r}\right)$, inductance $\left(L_{r}\right)$ & $0.816 \Omega, 0.002 \mathrm{H}$ \\
\hline Mutual inductance $\left(L_{m}\right)$ & $69.31 \times 10^{-3} \mathrm{H}$ \\
\hline Inertia $(\mathrm{J})$ & $0.089 \mathrm{Kg} . \mathrm{m}^{2}$ \\
\hline Friction factor $(\mathrm{B})$, poles $(\mathrm{P})$ & $0.005 \mathrm{~N} . \mathrm{m} . \mathrm{s}, 4$ \\
\hline
\end{tabular}

TABLE III

\begin{tabular}{|c||c|c|c|c|c|c|}
\hline \multicolumn{1}{|c||}{} & \multicolumn{3}{c|}{ Constant $\hat{\varphi_{r}}$} & \multicolumn{3}{c|}{ Dynamic $\hat{\varphi}_{r}$} \\
\hline Control & $\tau$ & $K_{p}$ & $K_{i}$ & $\tau$ & $K_{p}$ & $K_{i}$ \\
\hline$\omega_{r}$ & $40 \mathrm{~ms}$ & 2.225 & 0.125 & $40 \mathrm{~ms}$ & 2.225 & 0.125 \\
\hline$T_{e}$ & $10 \mathrm{~ms}$ & 0.367 & 170 & $10 \mathrm{~ms}$ & 0.367 & 170 \\
\hline$\hat{\varphi_{r}}$ & $10 \mathrm{~ms}$ & 5.572 & 2000 & $10 \mathrm{~ms}$ & 5.572 & 2000 \\
\hline$i_{q s}^{e}$ & $1 \mathrm{~ms}$ & 3.944 & 435 & $1 \mathrm{~ms}$ & 3.944 & 435 \\
\hline$i_{d s}^{e}$ & $1 \mathrm{~ms}$ & 71.31 & 435 & $1 \mathrm{~ms}$ & 3.944 & 435 \\
\hline
\end{tabular}

During the simulation, there are three variables changed separately. The total simulation time is 10 second. Before $1 \mathrm{~s}$, the induction motor sped up. At $2 \mathrm{~s}, T_{m}$ had a step response from 0 to $10 \mathrm{~N} . \mathrm{m} . T_{e}$ is always following the variation of $T_{m}$, so in another word, $T_{e}$ was increased to $10 \mathrm{~N} . \mathrm{m}$ from 0 at 2 s. The corresponding response of each PI controller's input is shown in Fig.8. The black dash line presents the response speed of the system. It is located at $0.04 \mathrm{~s}$ after the step response $\left(\tau_{t e}=0.04 \mathrm{~s}\right)$. The left side is the plot related to a constant $\hat{\varphi}_{r}$ and the right side is related to a dynamic one. Because $i_{q s}^{e}$ is related to $T_{e}$, the step response of $T_{e}$ just causes $i_{q s}^{e}$ increase and other parameters kept the constant with a transient. After comparing both side, the right rotor flux plot had a smaller response than the left one.
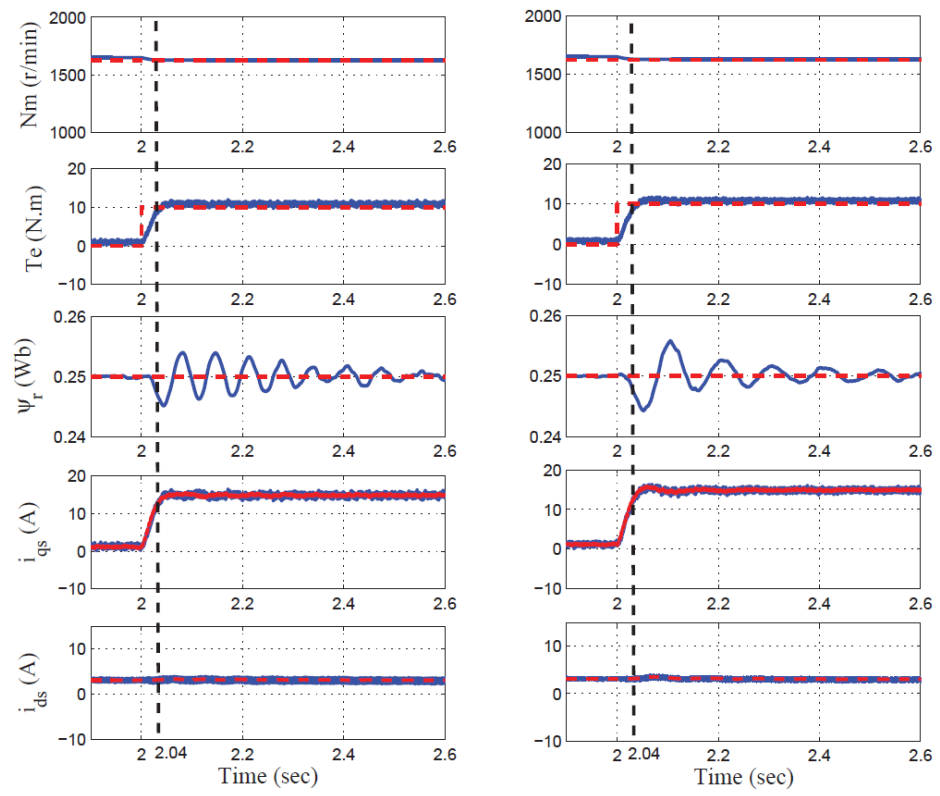

Fig. 8. At $2 \mathrm{~s}, T_{e}$ is changed from 0 to $10 \mathrm{~N}$.m. Constant $\hat{\varphi_{r}}$ (left); dynamic $\hat{\varphi_{r}}$ (right). Dotted red line (reference); solid blue line (measurement)

At $5 \mathrm{~s}$, the rotor speed, $N_{r}$, was reduced to 1432 from 1623r/min. In Fig. 9. It is observed that other PI controllers' inputs kept the constant when $N r$ was changed. Although it is related to $N_{r}, T_{e}$ always follows $T_{m}$ which is constant after $2 \mathrm{~s}$. Fig.9 proves that $T_{e}$ is independent to $N_{r}$ and $\hat{\varphi}_{r}$. Moreover, the right plots had a obviously faster and smaller response than the left.

At 8s, a step response happened on $\hat{\varphi}_{r}$ which was increased to 0.35 from $0.25 \mathrm{~Wb}$. In Fig.10, $i_{d s}^{e}$ was increased a little because its reference is the output of $\hat{\varphi}_{r}$. The decrease of $i_{q s}^{e}$ can be explained by (16). When $T_{e}$ and $P$ are constant, $i_{q s}^{e}$ is inversely proportional to $\hat{\varphi}_{r}$. In Fig.10, the right plots also had the faster and smaller response.

In a conclusion, the figures shows when the value of one variable among $T_{e}, N_{r}$, and $\hat{\varphi}_{r}$, was changed, the other two kept the constant with a short transient. It is [proved that the vector control loops of these two systems with a MMC worked well because the three variables can be controlled independently of each other. However, it is observed that the right side plots had a faster and smaller response than the left ones, hence, the vector control loop considering a dynamic $\hat{\varphi}_{r}$ works better than one assuming a constant flux.

\section{CONClusion}

As a kind of converter more applied for the medium and high voltage power applications, a 5-level MMC is used to 

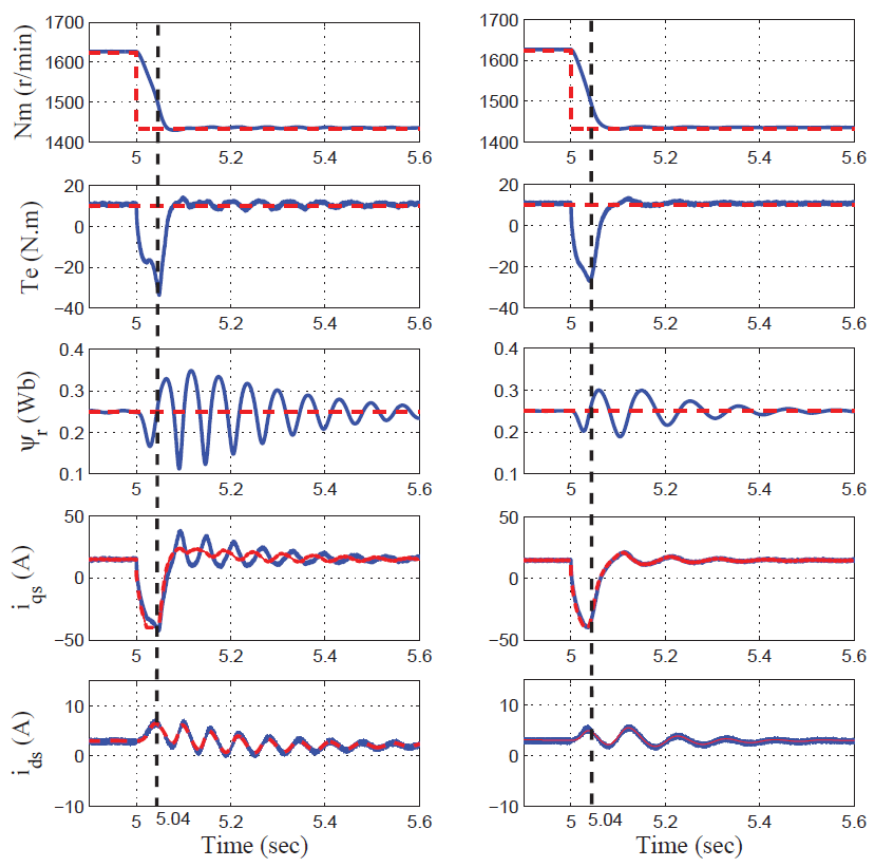

Fig. 9. At $5 \mathrm{~s}, N_{r}$ is changed from 1623 to $1432 \mathrm{r} / \mathrm{min}$. Constant $\hat{\varphi}_{r}$ (left) dynamic $\hat{\varphi_{r}}$ (right). Dotted red line (reference); solid blue line (measurement)
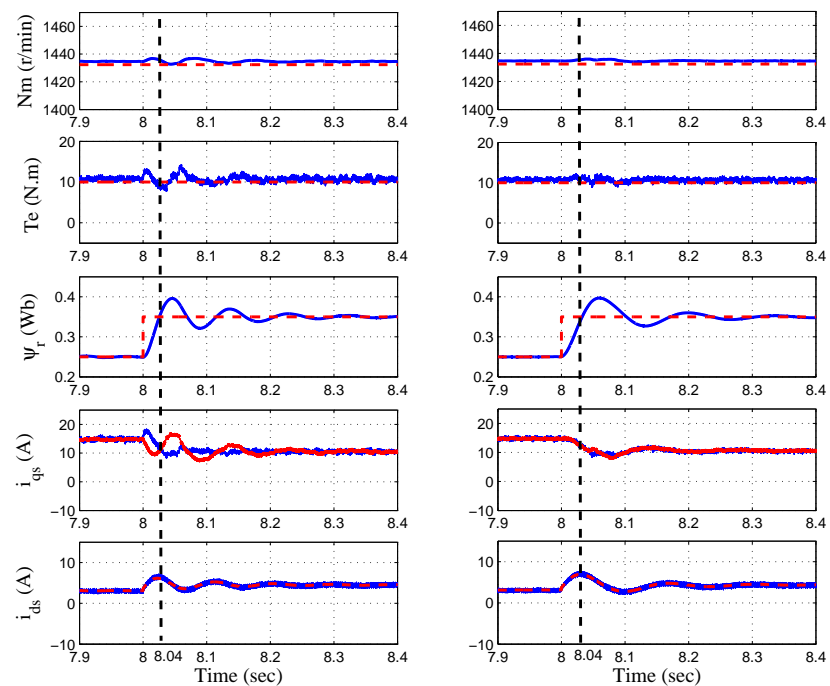

Fig. 10. At $8 \mathrm{~s}, \hat{\varphi_{r}}$ is changed from 0.25 to $0.35 \mathrm{~Wb}$. Constant $\hat{\varphi_{r}}$ (left); dynamic $\hat{\varphi_{r}}$ (right). Dotted red line (reference); solid blue line (measurement)

drive an induction motor. The simulation result proves that the MMC can take place of the traditional VSC. Hence, it is believed that the MMC has a further purpose in the area of the motor drive like wind farms. The issue which $\hat{\varphi}_{r}$ should be considered as a constant or dynamic in the vector control has been addressed. According to the arithmetic analysis and simulation results, a vector control with considering a constant $\hat{\varphi}_{r}$ in the inner loop is relatively simple and works well. However, after considering a dynamic $\hat{\varphi}_{r}$, the vector control loop is decoupled completely, so the vector control with a dynamic $\hat{\varphi}_{r}$ works more accurately and is better applied for the fast inner loop.

\section{REFERENCES}

[1] Y. Ma, Z. Miao, V. R. Disfani, and L. Fan, "A one-step model predictive control for modular multilevel converters," in PES General MeetingConference \& Exposition, 2014 IEEE. IEEE, 2014, pp. 1-5.

[2] Y. Ma, L. Fan, and Z. Miao, "Integrated control and switching strategy for a grid-connected modular multilevel converter."

[3] Y. Han, "Design, modeling, and control of multilevel converter motor drive with modular design and split winding machine," in Control and Modeling for Power Electronics (COMPEL), 2014 IEEE 15th Workshop on, June 2014, pp. 1-10.

[4] M. Hagiwara and H. Akagi, "Control and experiment of pulsewidthmodulated modular multilevel converters," Power Electronics, IEEE Transactions on, vol. 24, no. 7, pp. 1737-1746, July 2009.

[5] Q. Tu, Z. Xu, and L. Xu, "Reduced switching-frequency modulation and circulating current suppression for modular multilevel converters," Power Delivery, IEEE Transactions on, vol. 26, no. 3, pp. 2009-2017, July 2011.

[6] Q. Tu, Z. Xu, H. Huang, and J. Zhang, "Parameter design principle of the arm inductor in modular multilevel converter based hvdc," in Power System Technology (POWERCON), 2010 International Conference on, Oct 2010, pp. 1-6.

[7] Y. Zhou, D. Jiang, P. Hu, J. Guo, Y. Liang, and Z. Lin, "A prototype of modular multilevel converters," Power Electronics, IEEE Transactions on, vol. 29, no. 7, pp. 3267-3278, July 2014.

[8] X. Lin, K. Ou, Y. Zhang, H. Guo, and Y. Chen, "Simulation and analysis of the operating characteristics of mmc based vsc-mtdc system," in Innovative Smart Grid Technologies Europe (ISGT EUROPE), 2013 4th IEEE/PES, Oct 2013, pp. 1-5.

[9] X. Li, W. Liu, Q. Song, H. Rao, and S. Xu, "An enhanced mmc topology with dc fault ride-through capability," in Industrial Electronics Society, IECON 2013 - 39th Annual Conference of the IEEE, Nov 2013, pp. 6182-6188.

[10] N. Ahmed, A. Haider, D. Van Hertem, L. Zhang, and H.-P. Nee, "Prospects and challenges of future hvdc supergrids with modular multilevel converters," in Power Electronics and Applications (EPE 2011), Proceedings of the 2011-14th European Conference on, Aug 2011, pp. 1-10.

[11] K. Ilves, A. Antonopoulos, S. Norrga, and H.-P. Nee, "Steady-state analysis of interaction between harmonic components of arm and line quantities of modular multilevel converters," Power Electronics, IEEE Transactions on, vol. 27, no. 1, pp. 57-68, Jan 2012.

[12] L. Harnefors, A. Antonopoulos, S. Norrga, L. Angquist, and H.-P. Nee, "Dynamic analysis of modular multilevel converters," Industrial Electronics, IEEE Transactions on, vol. 60, no. 7, pp. 2526-2537, July 2013.

[13] B. K. Bose, in Modern Power Electronics and AC Drivers. PrenticeHall, Englewood Cliffs, New Jersey, 1986. 